\title{
CHARACTERIZATIONS AND OPTIMIZATION STUDY ON INFLUENCE OF DIFFERENT PARAMETERS ON FABRICATED SPHERICAL NANOPARTICLES FROM STREPTOMYCES SP. GUT 21
} (KU500633)

\author{
Pramod P Desai $^{1^{*}}$, Prabhurajeshwar ${ }^{2}$, B.V.Hudge ${ }^{3}$, Krishnaraj P $\mathbf{U}^{4}$, Kelmani Chandrakanth $\mathbf{R}^{5}$ \\ ${ }^{1,2,5}$ Medical Biotechnology and Phage Therapy Laboratory, Department of Post Graduate Studies and Research in \\ Biotechnology, Gulbarga University, Gulbarga-585 106, Karnataka, India \\ ${ }^{3,4}$ Deparment of Biotechnology, University of Agricultural Sciences, Krishinagar, Dharwad-580005, Karnataka, India \\ ${ }^{*}$ Corresponding author: Prof. Kelmani Chandrakanth R, Medical Biotechnology and Phage Therapy Laboratory, \\ Department of Post Graduate Studies and Research in Biotechnology, Gulbarga University, Gulbarga-585 106, \\ Karnataka, India. \\ Tel:09886361099,E-mail: pramod1to3@gmail.com
}

\begin{abstract}
A new technological approach was used for the production of silver nanoparticles using metal acquiring microorganism as a means of fabrication and making of superior biomaterials. Silver nanoparticles (AgNPs) are nanoparticles of silver which are in the range of 1 and $100 \mathrm{~nm}$ in size. Extracellular synthesis of AgNPs was observed when Streptomyces species was exposed to colloidal silver salt solution optimised at $1 \mathrm{mM}$ ionic strength by autoclaving method.UV-Visible spectroscopic analysis were done to monitor the drift in change of $\mathrm{pH}$, precursor concentration, Streptomyces supernatant volume and effect of temperature on the formation of AgNPs. Influence of different factors such as $p^{H}$, initial silver molar strength, water dilution, and methodology used o synthesize nanoparticles were found to be extremely reliable for consistent stability and storage purpose. The results indicated that temperature optimised was at $28^{0} \mathrm{C}$ for storage, $p^{H}$ was at neutral 7 and water orchestrated as "diluent", showed increased Nano-particle spectra. The formation of nanoparticles was first monitored by measuring the surface plasmon resonance (SPR) band at 410nm by UV-Visible absorption spectroscopy. The presence of elemental silver and the crystalline structure of the AgNPs were confirmed by Thermogravimetric analysis (TGA) and Powder X-ray diffraction (PXRD).In addition, Atomic Force Microscopy (AFM) along with FESEM imaging used for characterising nanoparticles revealed that they in spherical shape with an average particle size of 20-70nm. Finally, FTIR investigations revealed that many efficient clusters of functional bio molecules are playing significant role in capping and synthesis process.
\end{abstract}

Keywords: Antagonism, Silver Nanoparticles (AgNPs), 16S Ribosomal Gene, Atomic Force Microscopy (AFM).

\section{INTRODUCTION}

Nanotechnology arena has been one of the significant happenings research fields of $21^{\text {st }}$ century to exploit the distinctive and attractive properties of atoms, molecules clustered in nanometre range. Nanomaterials are being actively synthesized and researched for specific functions such as microbial growth inhibition, as carriers of antibiotics and as killing agents by utilizing culture filtrates/supernatant or biomass of the actinomycetes. Among the metal nanoparticles, silver nanoparticles (AgNPs) have become the much focus of extensive research due to their wide ranges of applications [1]. AgNPs have several characteristics that make them useful in many different areas of science, medicine, agriculture and catalysis [2]. These applications strongly depend on the properties of the produced AgNPs such as particle size and shape, size distribution and the surface charge [3]. Therefore, the control of these properties has become a major confront in research.
Blending of nanoparticles by utilizing microorganisms has come into view as a smooth, feasible and a green approach compared to chemical and physical methods. Natural biological assets like plants, including bacteria, fungi, yeasts and algae can be used for the synthesis of AgNPs but among them prokaryotic organisms have received the most consideration in this area. Prior studies have shown that culture supernatant extract of some bacterial genera, like Bacillus, Arthrobacter, Pseudomonas and E.coli could influence the synthesis of silver nanoparticles [4-6].Among Actinomycetes, Streptomyces genus is predominantly present in soil and decaying vegetation produce a lot of complex secondary metabolites. Also, previously reported, the cell-free supernatant extract of Streptomyces cyaneus strain Alex-SK121 isolated from sediment samples collected from Egypt was found to reduce $\mathrm{Ag}^{+3}$ ions to AgNPs by gamma irradiation process[7]. 
Nevertheless, a detailed scientific literature survey on nanoparticles synthesis has revealed that not much focus has been emphasized on the factors involved during synthesis process. Improving the properties of nanoparticles like firmness, storage and temperature control is an important step in achieving these goals. The studies have revealed that the size, morphology, stability and properties of the metal nanoparticles are strongly influenced by the experimental conditions, the kinetics of interaction of metal ions with reducing agents, and adsorption processes of stabilizing agent with metal nanoparticles [8, 9]. Hence, the devise of a synthesis method in which the size, morphology, stability and properties are control-led has become a major field of interest [10].Thus, in the present investigation optimization of different parameters were done like $\mathrm{p}^{\mathrm{H}}$, temperature, precursor concentration $\left(\mathrm{AgNO}_{3}\right)$ and water dilution factor on synthesized nanoparticles. In our previous research, various aspects of AgNPs synthesis have been studied and characterized however; here optimization revision was done on synthesized nanoparticles by using a basic technique of UV-Visible spectroscopy. Uv-visible absorption spectra have been proved to be quite sensitive to the formation of silver colloids because silver nanoparticles exhibit an intense absorption peak due to the surface plasmon (as it describes the collective excitation of conduction electrons in a metal) excitation[11].Consequently, this property was exploited for optimization of fabricated nanoparticles during synthesis procedure. The particle size and shape of synthesized nanoparticles was inferred by employing the techniques like X-Ray diffraction and atomic force microscopy. In continuation, Thermogravimetric analysis or (TGA) was done to study the changes in physical and chemical properties of nanoparticles which were measured as a function of increasing temperature with constant heating rate. FESEM technique was also used to understand the morphology of the biosynthesised AgNPs. Further, FTIR spectroscopic investigations were done to understand the different functional groups of the bio molecules involved in synthesis of AgNPs.

\section{EXPERIMENTAL}

\subsection{Materials and Methods}

All the analytical grade chemicals were used during entire research methodology. The media ingredients like Agar, Malt extract powder and $\mathrm{AgNO}_{3}$ were acquired from S.D. Fine Chemicals, Mumbai, India. Ultrapure water was used for all the experimentation.

\section{Isolation, Screening and Molecular identification}

Isolation of various morphologically different actinomycetes species was carried out from soils sampled from diverse ecological niches including the campus of Gulbarga University; Gulbarga as reported previously. Preliminarily, these isolated actinomycetes strains were then screened with regard to their potential to generate bioactive compounds [12] against pathogenic organisms by cross streak method [13] as shown in Fig. 1.ISP-2 Media plates containing Agar were prepared and inoculated by a single line streak perpendicular in the centre of petriplate and incubated at $28^{\circ} \mathrm{C}$ for 7 days. The plate was then inoculated with the pathogenic organisms by a single streak at $90^{\circ}$ angle and incubated at $37^{\circ} \mathrm{C}$ overnight. Antagonism along the surrounding of the plate was viewed by the inhibition of test organism. Further, this potent strain was carried forward for its morphological and molecular taxonomic identification and evolutionary phylogeny relationship was identified by 16S ribosomal gene amplification as shown in Fig.2 (a). The PCR amplicon products were analysed in $1 \%$ agarose gel by electrophoresis and purified by using PCR purification kit (QIAGEN). The 16S rDNA gene sequencing was outsourced at a sequencing facility available at XCELERIS Labs (Ahmadabad, India).The DNA sequence obtained was then mapped by BLAST hit similarity at the NCBI database and the sequence was deposited in Gene Bank with an Accession number KU500633. The 16S rRNA gene sequence of the strain Streptomyces sp. GUT 21 was aligned with reference sequences retrieved from GenBank and the Phylogenetic tree was constructed using the neighbourjoining method with MEGA 6 software Fig.2 (b).

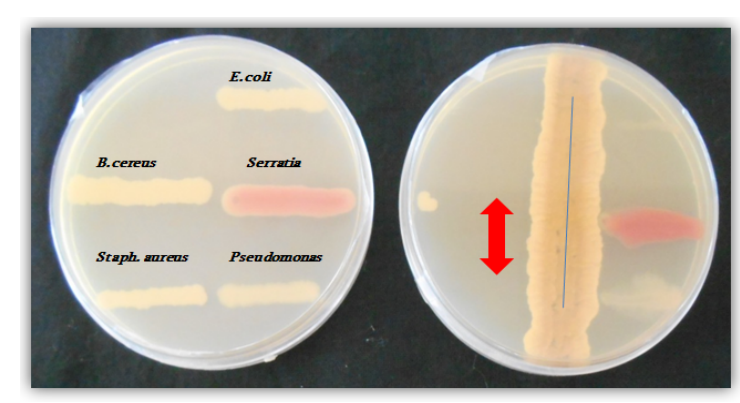

Fig. 1 A-Control plate, B-Streptomyces sp. GUT 21 Strain showing antagonism.

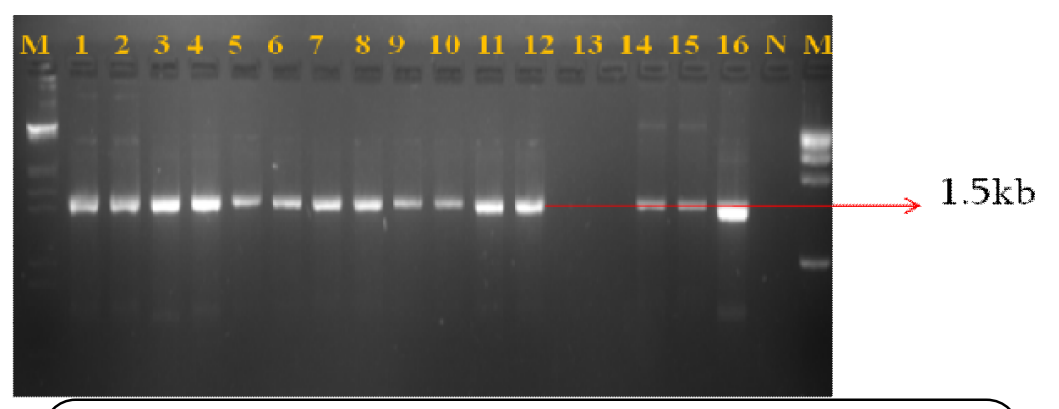

Fig. 2 (a) $16 \mathrm{~S}$ ribosomal DNA gene amplification by PCR using the universal primer pair of potent Actinomycetes isolates. Lane

M: Double Digest Marker, Lane 1-12: Streptomyces GUT isolates. $11^{\text {th }}$ Lane GUT 21. N-Negative Control. M-1Kb Marker. 


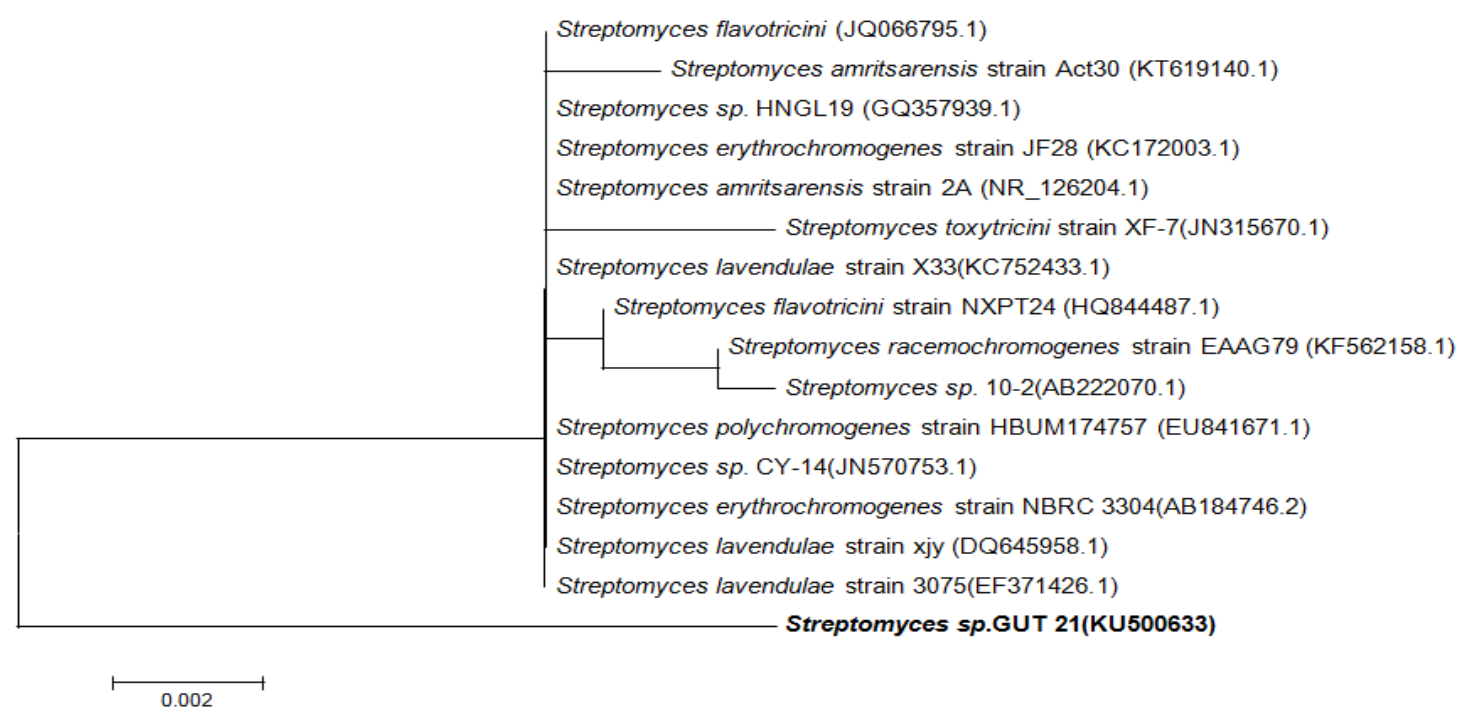

Fig. 2 (b) The phylogenetic tree of Streptomyces. sp GUT 21 (KU500633) was generated via neighbour-joining algorithm with the help of MEGA 6 software version. Bar 0.002 represents scale substituted for each nucleotide position.

\section{Preparation of Actinomycetes extract}

Preparation of the Streptomyces sp. GUT 21 extract was grown in Yeast extract-malt extract Broth (ISP-2) containing (g/L) Yeast extract-4g, Malt extract-10g, Dextrose-4g, Distilled water $1000 \mathrm{ml}$ for 10 days at $200 \mathrm{rpm}$ shaking conditions. After the incubation period, the aqueous extract was centrifuged at 13000rpm for 10minutes.This supernatant extract was further filtered through Whattman filter paper and employed for the biosynthesis of nanoparticles. Centrifugation and filtration of the extract was followed to remove all debris material (like hyphae and mycelium) from the isolate and stored in deep freezer for further analysis.

\section{Biofabrication of AgNPs using Streptomyces genus}

For fabrication of silver nanoparticles, $100 \mathrm{mM}$ of silver nitrate colloidal solution was prepared and used for synthesis process. Optimized $10 \mathrm{ml}$ of Streptomyces sp.GUT 21 supernatant extract was added to the $250 \mathrm{ml}$ Erlenmeyer flask containing $1 \mathrm{ml}$ of $\mathrm{AgNO}_{3}(1 \mathrm{mM})$, volume made up to $100 \mathrm{ml}$ by distilled water and processed further. This solution was further autoclaved at $121^{\circ} \mathrm{C}$ for 15 minutes for $15 \mathrm{lbs}$ and left to cool at room temperature in dark conditions. The reduction process of $\mathrm{Ag}^{+}$ion to $\mathrm{Ag}^{0}$ nanoparticles was then followed by the physical change in the colour of solution from pink to dark brown yellow colour in autoclaving process as shown in Fig. 3. In order to monitor the silver nanoparticle synthesis, the samples were measured in Ultraviolet visible region (Varian Cary 50 Bio Uv-VIS Spectrophotometer) from a wavelength scan range from 200 to $800 \mathrm{~nm}$. A control reaction mixture was also maintained without actinomycete extract.

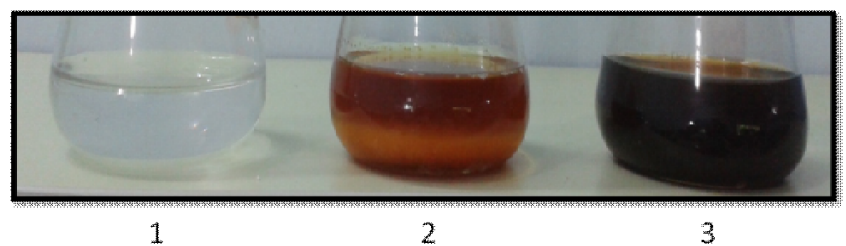

Fig. 3 1- Control $\mathrm{AgNO}_{3}$, 2- Streptomyces sp. GUT 21 extract, 3- AgNPs synthesized.

\section{CHARACTERIZATION AND OPTIMIZATION} OF SILVER NANOPARTICLES SYNTHESIS

\subsection{UV-Vis Spectroscopy Analysis}

The formation of the AgNPs in the solution was monitored by UV-Visible spectrophotometer (Varian Cary 50 Bio UVVIS Spectrophotometer) by using distilled water as blank in reference mode.UV-Visible spectrum was confirmed in the wavelength range of $200-800 \mathrm{~nm}$ at a resolution of $1 \mathrm{~nm}$. Change in colour was visually observed to dark brown colour in the solution synthesized with Streptomyces sp.GUT 21 extract. This peak spectrum was also authenticated by taking the reading in Nanodrop spectrophotometer (Model ND-1000 version 3.5, USA).

\subsection{Optimization of Different Parameters}

Optimization of different parameters like temperature, $\mathrm{p}^{\mathrm{H}}$, precursor concentration and water dilution factors were done on synthesised silver Nanoparticles (AgNPs) to get uniform sized and stable silver nanoparticles.

\subsection{PXRD Measurements}

Powder X-Ray diffraction (PXRD) pattern was studied for the synthesized AgNPs using ( $\mathrm{Cu}-\mathrm{K} \alpha$ radiation source) using a $12 \mathrm{~kW}$ rotating $\mathrm{Cu}$ anode based Bruker (Smart Apex II) powder diffractometer (Model Small Apex-II) operating in Bragg-Brentano geometry. The scanning dimension (2Ө) value was selected from 20 to 80 angles. Finally, the 
average crystallite size (D) was estimated from the line augmentation in PXRD by means of Debye Scherer's formula.

\subsection{Thermogravimetric Analysis (TGA)}

The degradation pattern and thermal stability of the powdered sample of AgNPs were done synthesized from Streptomyces supernatant filtrate using a TA INSTRUMENTS, (USA) by Thermogravimetric analyzer (TGA) apparatus above a temperature range of $28-600^{\circ} \mathrm{C}$ at a heating rate of $10^{\circ} \mathrm{C} / \mathrm{min}$ in the presence of $\mathrm{N}_{2}$ gas. The weight of the sample taken for each record was approximately $2-3 \mathrm{mg}$.

\subsection{Field-Emission Scanning Electron Microscopic Illustration of AgNPs}

Field Emission scanning electron microscopy was done to understand the morphological and elemental information of silver nanoparticles. Image dimensions were captured on a JEOL JSM-7600F (USA) instrument accomplished at an accelerating voltage of $15 \mathrm{kV}$.

\subsection{Atomic Force Microscopy of Silver}

\section{Nanoparticles}

Morphological depiction of fabricated AgNPs from above Streptomyces extract was obtained by AFM technique. AFM analysis were executed using an AFM Explorer microscope (Thermo Microscopes, USA) in room temperature, with a non-contact mode through Si cantilevers of a 1650-00 type (Thermo Microscopes) with a nominal tilt radius of $10 \mathrm{~nm}$ and reverberating frequencies of about $220 \mathrm{kHz}$. Glass slides previously cleaned with sulphuric acid, hydrogen peroxide and deionized water were used as the substrate. For the sample preparation, thin films supplied with the instrument were kept for 24 hours at room temperature and then were submitted to a heat treatment at $80{ }^{\circ} \mathrm{C}$ for 2 hours and then coated on glass slide. The image measurements were carried out using SPM Lab software which included levelling on the plane, background fine adjustments and intermittent stripe removing with fine cantilever adjustments.

\subsection{FTIR investigations}

FTIR chemical functional group analysis of microbemediate fabricated AgNPs was performed on a NICOLET, USA (MODEL 6700) instrument in the disperse reflectance mode at a resolution of $4 \mathrm{~cm}^{-1}$ blended in $\mathrm{KBr}$ pellets and the spectrum was recorded in the wavelength range of 500 and $4000 \mathrm{~nm}^{-1}$.

\section{RESULTS AND DISCUSSIONS}

\section{UV-Visible Spectroscopy Investigation}

Fig. 4 represents UV-Visible spectra of a strong peak of SPR band with a maximum at $410 \mathrm{~nm}$ or at $409 \mathrm{~nm}$ (sometimes owing to particles getting aggregated due to storage) was observed by autoclaving method which corresponds to distinctive plasmon resonance of oscillating $\&$ conducting electrons on the surface of silver nanoparticles [11]. This band was a sign for formation of spherical nanoparticles in a reaction solution. However, the SPR peak absorption of metal nanoparticles like gold and silver is very susceptible to the changes of the size and shape of the nanoparticles formed [14]. Thus, this peak spectrum was also validated by taking the reading in Nanodrop spectrophotometer.

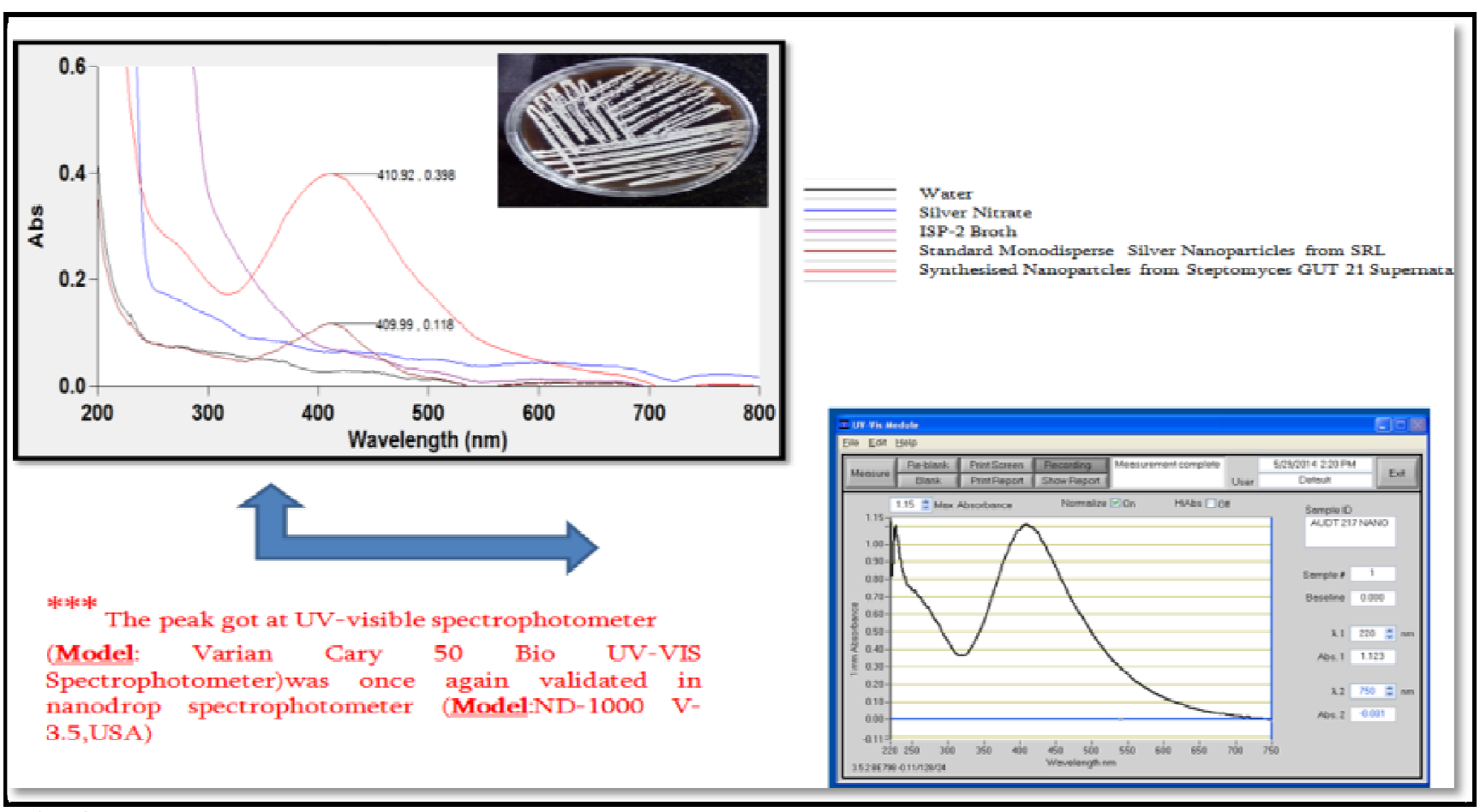

Fig. 4 UV-Visible peak representation of nanoparticles and its validation of spectral data in nanodrop spectrophotometer. 


\section{Effect of Temperature on Nanoparticles}

Fig.5 shows the optimization studies with respect to temperature carried out at different ambient temperature ranging from $-20^{\circ} \mathrm{C}$ to room temperature at $28^{\circ} \mathrm{C}$ for synthesized AgNPs. $10 \mathrm{ml}$ of the synthesized nanoparticle solution (in replicates) were incubated at different temperature for a period of one day to monitor temperature effect. These samples were then analyzed with UV-visible absorption spectroscopy and further effect of temperature on nanoparticles was studied. Temperature is an essential factor affecting AgNPs production to know the phenomenon of silver ion reduction. The maximum production and stability of AgNPs was attended at $28^{\circ} \mathrm{C}$ by change in color when compared with other lower temperatures and also the maximum peak absorption spectra detected in UV-visible spectroscopy was at 409nm which indicates the elevated production of AgNPs. However, on the other side at lower temperature of $4^{\circ} \mathrm{C}$, and $-20^{\circ} \mathrm{C}$ the particles strive to aggregate and the intensity of the peak also gets decreased (Table 1).

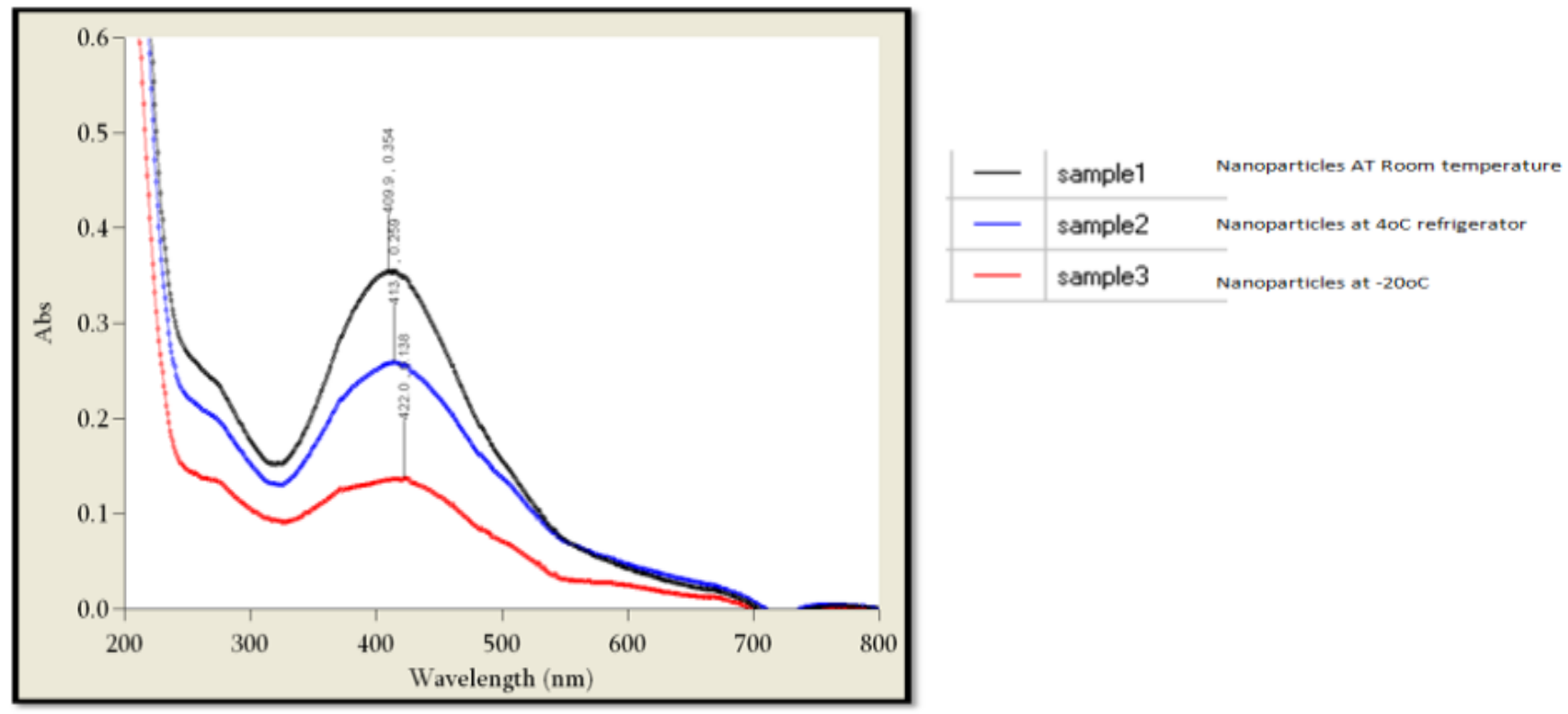

Fig. 5 UV-Visible spectral visualization of temperature changes in nanoparticles.

Table 1: UV-Visible spectral values of temperature effect on synthesized nanoparticles.

\begin{tabular}{|l|l|l|l|}
\hline SI.No & Temperature & Wavelength $(\mathbf{n m})$ & Absorption \\
\hline 1. & Room temperature $\left(28^{0} \mathrm{C}\right)$ & $409.9 \mathrm{~nm}$ & 0.354 \\
\hline 2. & Refrigerator $\left(4^{0} \mathrm{C}\right)$ & $413.0 \mathrm{~nm}$ & 0.259 \\
\hline 3. & Deep freezer $\left(-20^{0} \mathrm{C}\right)$ & $422.0 \mathrm{~nm}$ & 0.138 \\
\hline
\end{tabular}

\section{Effect of $p^{\mathrm{H}}$ on Nanoparticles}

For storage and stability intention, effect of $\mathrm{p}^{\mathrm{H}}$ was screened, which plays an important role on synthesized nanoparticle. Initially, $\mathrm{p}^{\mathrm{H}}$ of the Streptomyces supernatant extract was 8.36 and it changed to 6.25 when the reaction solution was fabricated in autoclaving process. This factor induces the reactivity of supernatant extract to bind with silver ions. $\mathrm{p}^{\mathrm{H}}$ of the nanoparticle solutions was sustained over a range from 2-14 adjusted with $1 \mathrm{~N}$ HCL and 1N $\mathrm{NaOH}$. Fig.6 shows the effect of $\mathrm{p}^{\mathrm{H}}$ on the synthesized nanoparticles and UV spectra recorded at different $\mathrm{p}^{\mathrm{H}}$ values as a function of time represented in Table 2 . We observed that at acidic $\mathrm{p}^{\mathrm{H}} 2$, there was no detection of peak where as at $\mathrm{p}^{\mathrm{H}} 4$ the peak was detected at $420 \mathrm{~nm}$ with less intensity. The lower absorbance in peak was observed in the acidic $\mathrm{pH}$ due to suppression of nanoparticles in the medium. As the $\mathrm{pH}$ goes on increasing gradually, the peak sharpens at neutral $\mathrm{p}^{\mathrm{H}}$. It can also be inferred that in the alkaline $\mathrm{p}^{\mathrm{H}} 8$ and 10 , nanoparticles synthesis was high by examining the physical colour change in Fig 6. In the alkaline $\mathrm{pH}$ the surface plasmon Resonance (SPR) band was positioned at $409 \mathrm{~nm}$ indicating particles might be are in small size. High stabilized nanoparticles were synthesized at the alkaline $\mathrm{pH}$ as reported previously by Saware et al [15]. In the lower pH state, nanoparticles get agglomerated and form large sized nanoparticles. Depending on their size and shape, anisotropy nanoparticles are expected to display one or more SPR bands. 

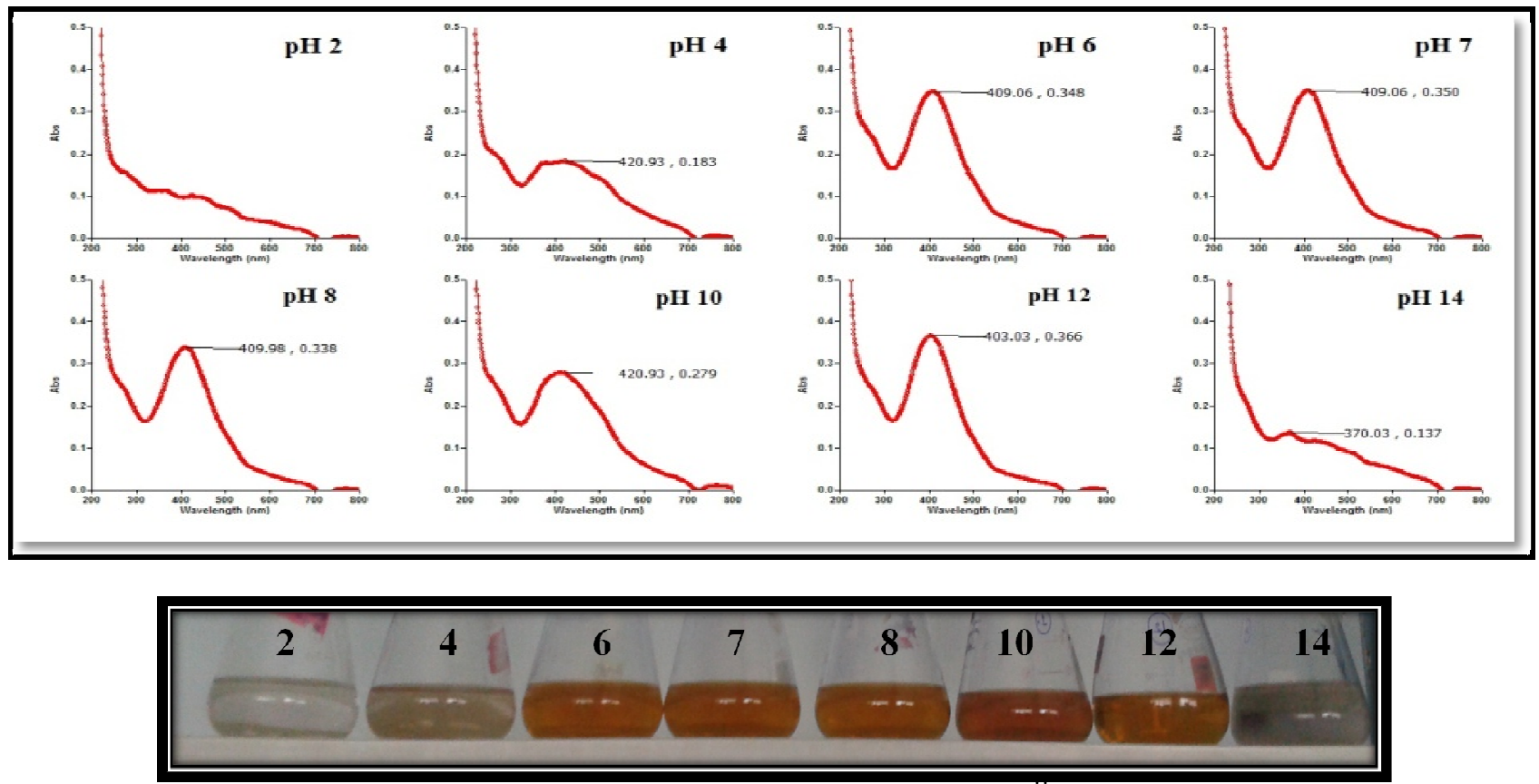

Fig. 6 Colour change monitoring and UV-Visible spectral data of $\mathrm{p}^{\mathrm{H}}$ Effect on nanoparticles.

Table 2: UV-Visible spectral values of $\mathrm{pH}$ effect on synthesized nanoparticles.

\begin{tabular}{|l|c|c|c|}
\hline Sl.No & pH & Wavelength $(\mathbf{n m})$ & Absorption \\
\hline 1. & 2 & - & - \\
\hline 2. & 4 & 420.93 & 0.183 \\
\hline 3. & 6 & 409.06 & 0.348 \\
\hline 4. & 7 & 409.06 & 0.350 \\
\hline 5. & 8 & 409.98 & 0.338 \\
\hline 6. & 10 & 420.93 & 0.279 \\
\hline 7. & 12 & 403.03 & 0.366 \\
\hline 8. & 14 & 370.03 & 0.137 \\
\hline
\end{tabular}

\section{Effect of Precursor concentration and extract}

\section{volume on Nanoparticles}

Biosynthesis of AgNPs with different concentrations of colloidal silver nitrate $\left(\mathrm{AgNO}_{3}\right)$ solution from $1 \mathrm{mM}$ to
$100 \mathrm{mM}$ was also studied with the Streptomyces GUT 21 filtrate. Since, the production of nanoparticles is also dependent on initial precursor concentration, the concentration of $\mathrm{AgNO}_{3}$ was varied from $1 \mathrm{mM}$ to $100 \mathrm{mM}$ with a difference of average difference of $25 \mathrm{mM}$. The optimum concentration for the biosynthesis of silver nanoparticles was substantiated by UV-VIS absorption spectroscopy. The optimum precursor concentration was optimized as $1 \mathrm{mM}$ by colour change and by UV-visible spectra at the maximum absorbance peak of $409 \mathrm{~nm}$ as seen in Fig. 7. Conversely, when the $\mathrm{AgNO}_{3}$ concentration is progressively increased there was no detection of nanoparticle synthesis and no SPR band was observed Table 3. Similarily, Dubey et. al [16] have also reported the decreasing drift in the configuration of silver nanoparticles with the increase of silver ion concentration.

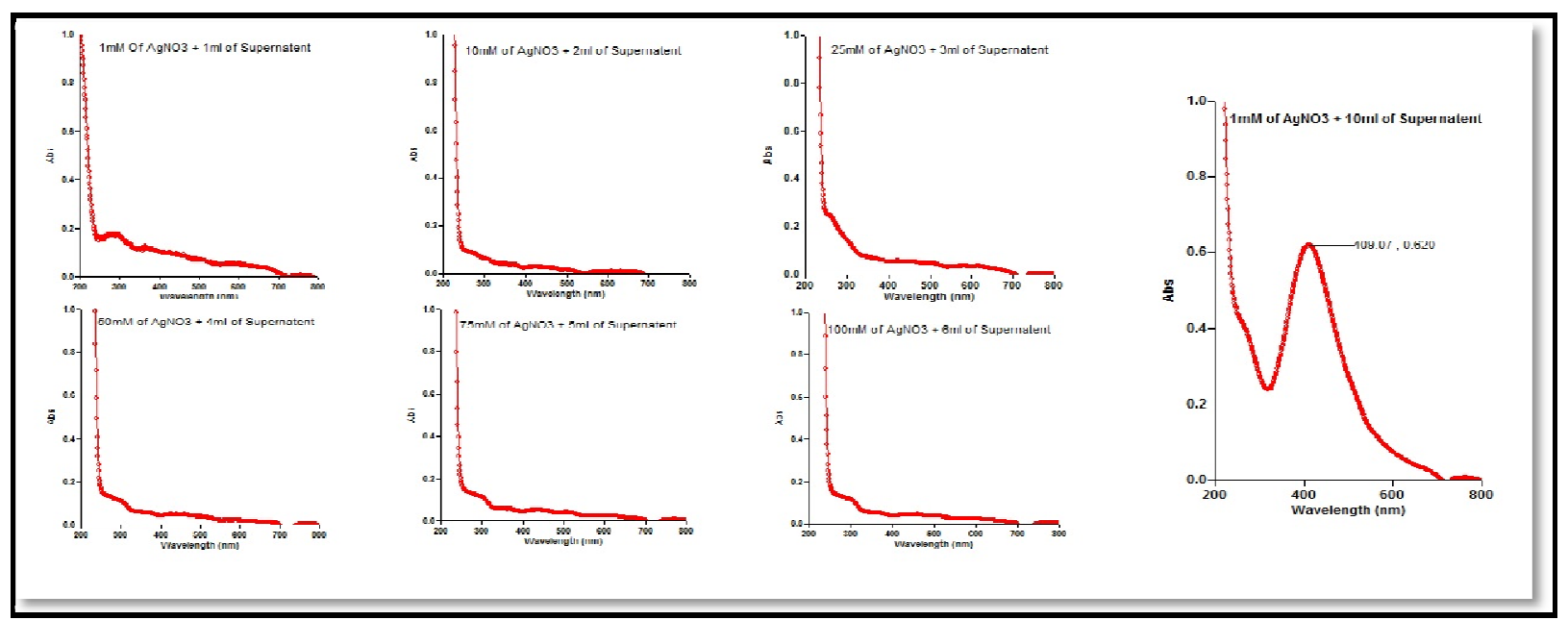

Fig. 7 UV-visible spectrum of silver nanoparticles synthesized by using altered volumes of Streptomyces GUT 21supernatent extract and precursor concentration. 
Table 3: UV-Visible spectral values of precursor concentration $\left(\mathrm{AgNO}_{3}\right)$ \& extract volume for nanoparticles synthesis.

\begin{tabular}{|c|c|c|c|c|}
\hline Sl.No & $\begin{array}{c}\text { Supernatant } \\
\text { volume (ml) }\end{array}$ & $\begin{array}{c}\text { Precursor concentration } \\
\mathbf{A g N O}(\mathbf{m M})\end{array}$ & Wavelength (nm) & Absorption \\
\hline 1. & $1 \mathrm{ml}$ & $1 \mathrm{mM}$ & - & - \\
\hline 2. & $2 \mathrm{ml}$ & $10 \mathrm{mM}$ & - & - \\
\hline 3. & $3 \mathrm{ml}$ & $25 \mathrm{mM}$ & - & - \\
\hline 4. & $4 \mathrm{ml}$ & $50 \mathrm{mM}$ & - & - \\
\hline 5. & $5 \mathrm{ml}$ & $75 \mathrm{mM}$ & - & - \\
\hline 6. & $6 \mathrm{ml}$ & $100 \mathrm{mM}$ & 409.07 & 0.620 \\
\hline 7. & $10 \mathrm{ml}$ & $1 \mathrm{mM}$ & - & - \\
\hline
\end{tabular}

\section{Effect of Water dilution on Nanoparticles}

Further, to ascertain the UV-visible spectra of nanoparticles synthesized, these particles were diluted in Millipore ultrafine distilled water with increasing the volume of nanoparticle solution. In most of the research experimental conditions, Water, which is considered as a "Universal solvent" was assessed to check the behaviour of nanoparticles in an electromagnetic spectrum. As the nanoparticle suspension goes on increasing, the intensity of the peak also goes on increasing with shuffling of particles (Table 4). The maximum detection peak of AgNPs was attended at $1000 \mu \mathrm{l}(1 \mathrm{ml})$ volume when compared with other dilutions as depicted in Fig. 8.

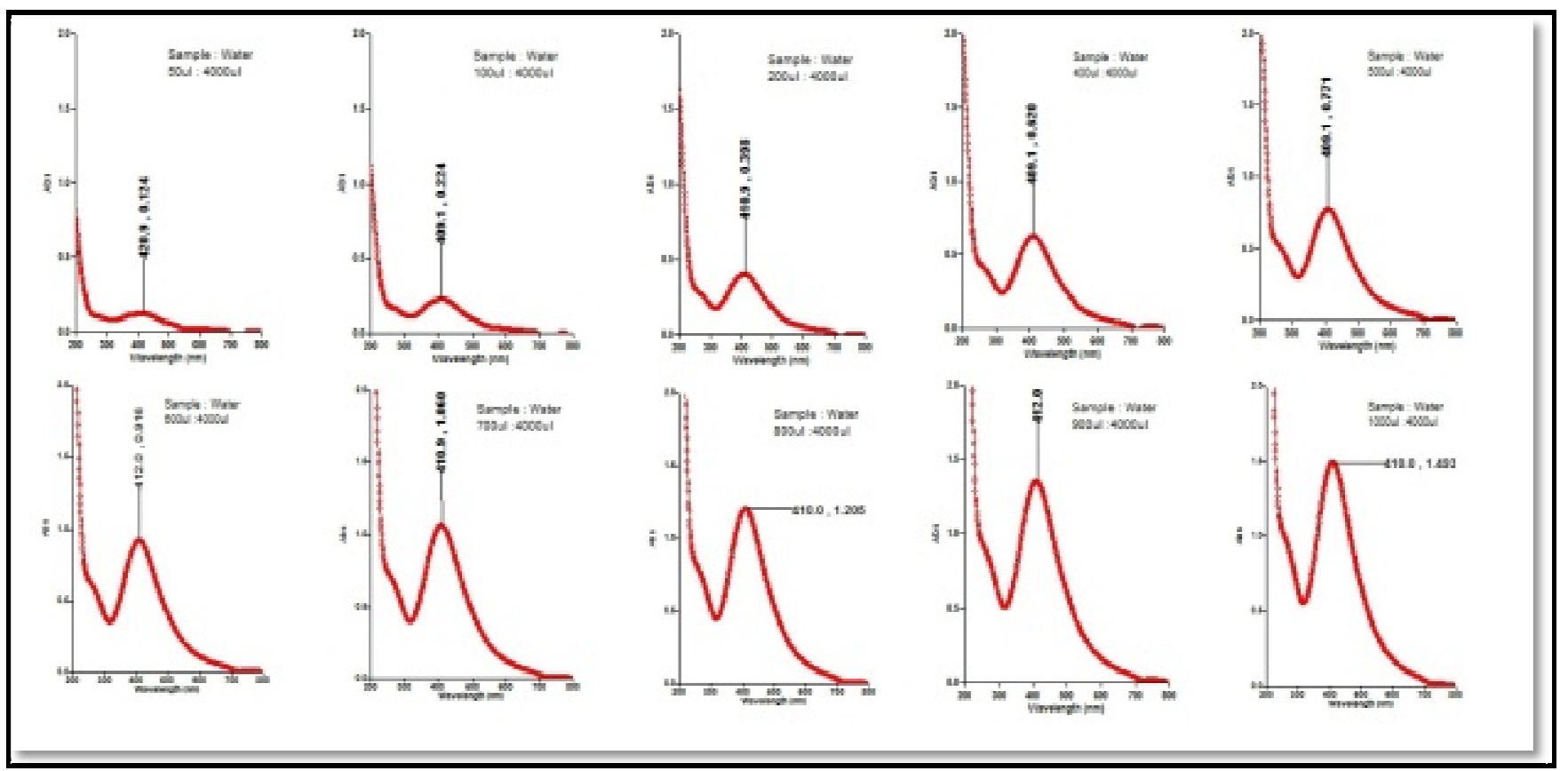

Fig.8 Effect of water dilution on synthesized nanoparticles.

Table 4: UV-Visible spectral values of water dilution concentration for nanoparticles synthesis.

\begin{tabular}{|c|c|c|c|c|}
\hline Sl.No & Nanoparticle solution & Water diluents & Wavelength $(\mathbf{n m})$ & Absorption \\
\hline 1. & $50 \mu \mathrm{l}$ & $4000 \mu \mathrm{l}$ & 420.09 & 0.124 \\
\hline 2. & $100 \mu \mathrm{l}$ & $4000 \mu \mathrm{l}$ & 409.01 & 0.224 \\
\hline 3. & $200 \mu \mathrm{l}$ & $4000 \mu \mathrm{l}$ & 410.09 & 0.398 \\
\hline 4. & $400 \mu \mathrm{l}$ & $4000 \mu \mathrm{l}$ & 409.01 & 0.620 \\
\hline 5. & $500 \mu \mathrm{l}$ & $4000 \mu \mathrm{l}$ & 409.01 & 0.771 \\
\hline 6. & $600 \mu \mathrm{l}$ & $4000 \mu \mathrm{l}$ & 412.00 & 0.916 \\
\hline 7. & $700 \mu \mathrm{l}$ & $4000 \mu \mathrm{l}$ & 410.90 & 1.060 \\
\hline 8. & $800 \mu \mathrm{l}$ & $4000 \mu \mathrm{l}$ & 410.00 & 1.205 \\
\hline 9. & $900 \mu \mathrm{l}$ & $4000 \mu \mathrm{l}$ & 412.00 & 1.351 \\
\hline 10. & $1000 \mu \mathrm{l}$ & $4000 \mu \mathrm{l}$ & 410.00 & 1.492 \\
\hline
\end{tabular}


Fig. 9 depicts a typical XRD pattern of the silver nanoparticles synthesized by the Streptomyces sp.GUT 21 supernatant extract after the complete reduction of $\mathrm{Ag}^{+}$to $\mathrm{Ag}^{0}$. Bragg reflections which were present in the diffractogram were marked on the basis of the face centered cubic (fcc) structure of silver. The diffraction peaks at $2 \theta=$ $24.6^{\circ}\left(\begin{array}{lll}1 & 0 & 0\end{array}\right), 28.3^{\circ}\left(\begin{array}{lll}1 & 1 & 0\end{array}\right), 44.5^{\circ}\left(\begin{array}{lll}2 & 0 & 0\end{array}\right)$ and $65.6^{\circ}(2 \quad 20)$ obtained are identical with those reported for the standard silver metal. (Joint Committee on Powder Diffraction
Standards-JCPDS, USA). The average crystallite size (D) was estimated from the line augmentation in PXRD by means of Debye Scherer's formula $\mathrm{D}=\frac{\mathrm{K} \lambda}{\beta \cos \theta}$ and was found in the range of $15-20 \mathrm{~nm}$. Thus, the diffraction arrangement suggests that the silver nanoparticles were essentially crystalline in nature. Similar results were too reported earlier for silver nanoparticles [17].

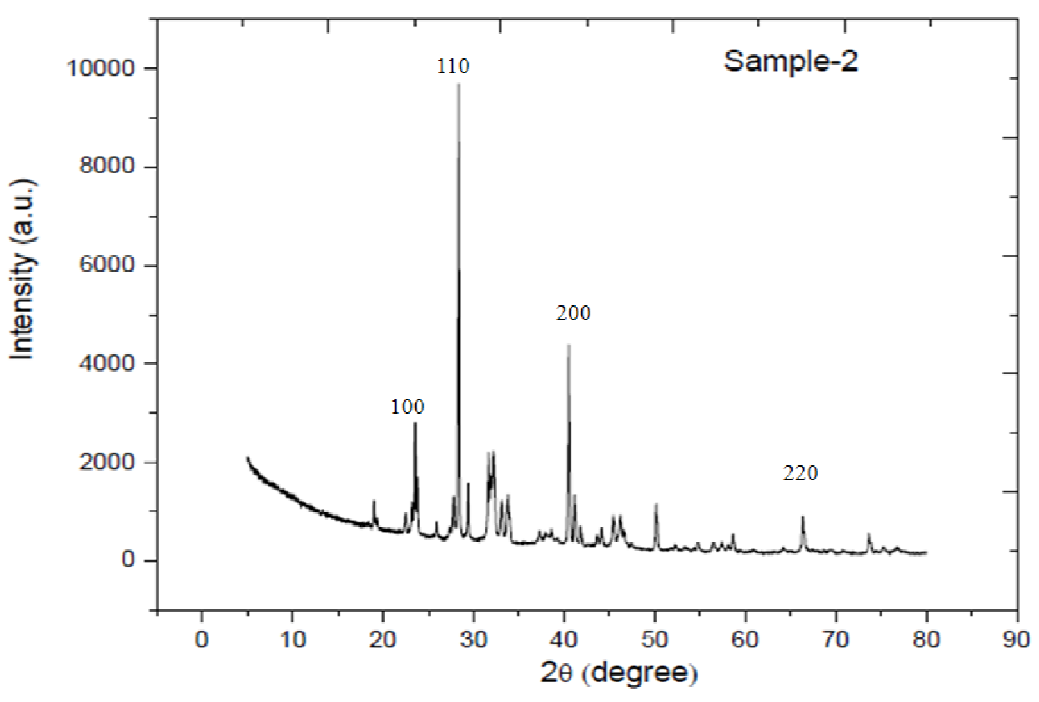

Fig. 9 The diffractogram obtained in Powder X-RAY (PXRD) diffraction studies.

Fig.10 portrays TGA thermal curve of AgNPs displaying temperature unit on $\mathrm{x}$-axis against $\%$ weight loss component on y-axis. The thermal graph demonstrates curving two stride weight losses with a total weight loss of $9.515 \%$ of the AgNPs sample and $0.51346 \mathrm{mg}$ of the debris retaining in crucible heated at $60.94^{\circ} \mathrm{C}$ under nitrogen flow. Further, the curvature extending from $100^{\circ} \mathrm{C}$ to $400^{\circ} \mathrm{C}$ exhibits weight loss is probably owing to capping of secondary metabolites over the surface of AgNPs. Additionally, it entails that the sample has been melted with complete decomposition of metallic silver. The consistent weight loss occurring between ambient temperature and $600^{\circ} \mathrm{C}$ corresponds to removal of absorbed water molecules. Pure silver microstructures are remained in the residue after the total reduction of metal oxides.

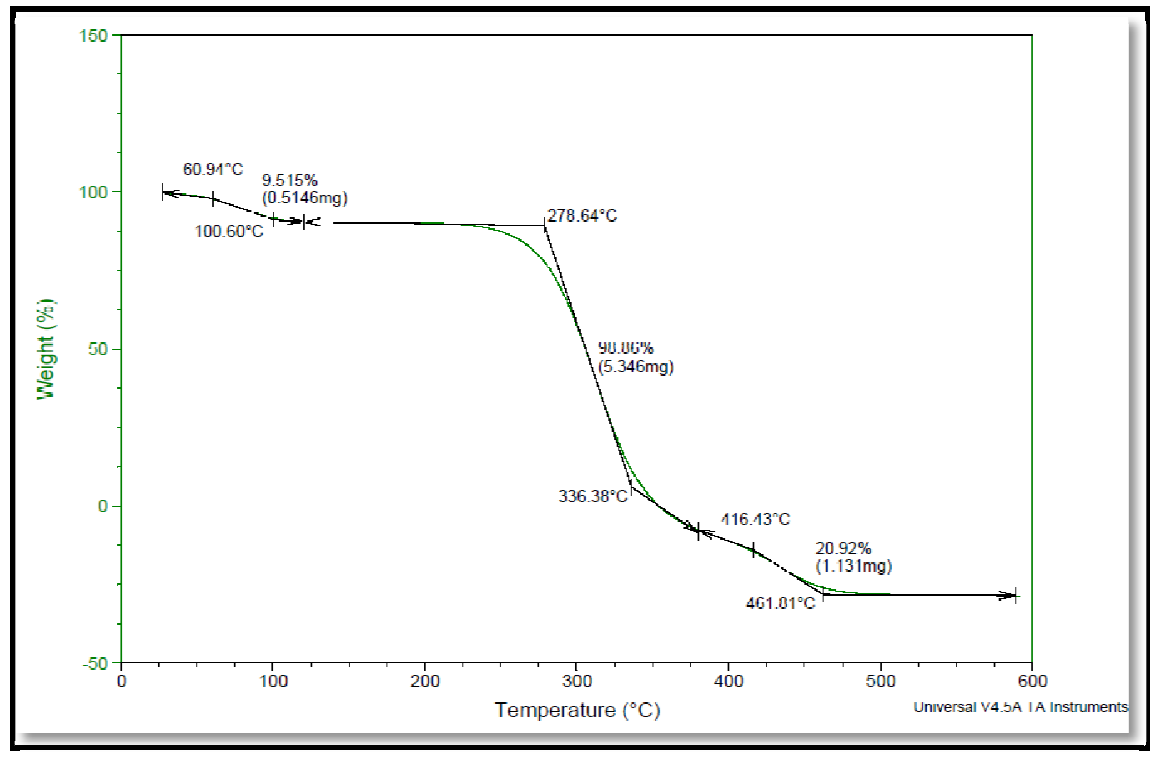

Fig.10 TGA spectra of silver nanoparticles. 
FESEM images of the samples obtained from the colloidal Ag solutions prepared at $80^{\circ} \mathrm{C}$, confirms the existence of very small and uniformly spherical nano particles as shown in Fig. 11.These nanoparticles are spherical, polydispersed but are highly aggregated. It can be observed that larger particles of AgNPs are formed owing to aggregation of nano particles which might be prompted by the dehydration of solvent during sample preparation. This could have added for the discrepancy in particle size. Thus, it can be attributed that synthesized nanoparticles are in the range of $20-70 \mathrm{~nm}$ in size with some nanospheres in the regime of $15-20 \mathrm{~nm}$.

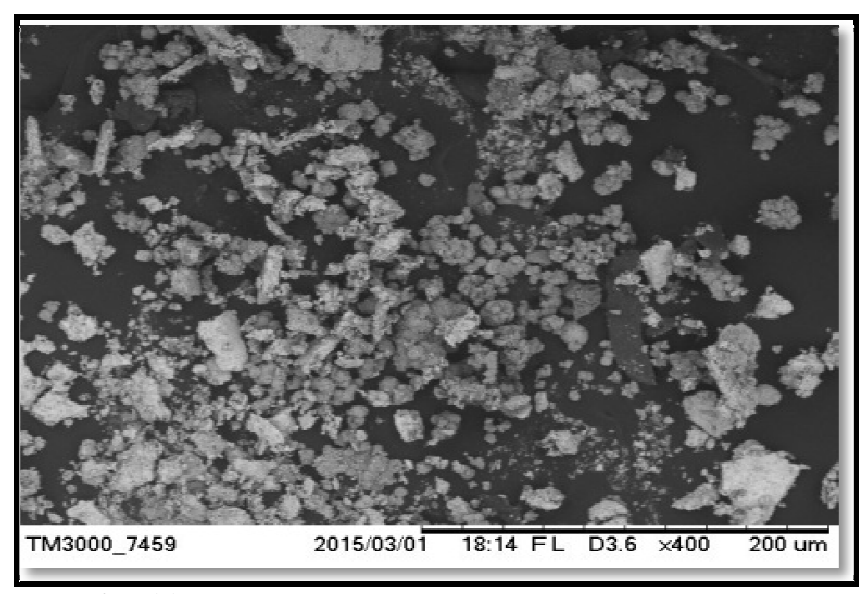

Fig. 11 FESEM image of AgNPs synthesized using supernatant of Streptomyces sp. GUT 21 depicting at a scale bar of $200 \mu \mathrm{m} \&$ magnification $400 \mathrm{X}$.
AFM is a preferably suited characterized technique which tenders the ability of revealing 3D structural images of AgNPs. It gives a typical knowledge on both qualitative and quantitative data on many physical properties along with size, morphology, surface texture and roughness of synthesized nanoparticles. With a single topology scan, statistical information, including size, surface area, and volume distributions, can also be resolved together by cantilever adjustments. From the topographical view, Fig. 12 , it is apparent that the most of the nanoparticles are in spherical shape with an average particle size of $30-85 \mathrm{~nm}$ in thickness with an average size of about $38 \mathrm{~nm}$ in length which was much larger than that of estimated values from XRD data. This variation in particle size is might be due to the difficulty of precise cantilever tip attachment to the exact sample end and also during setting up of AFM test samples.
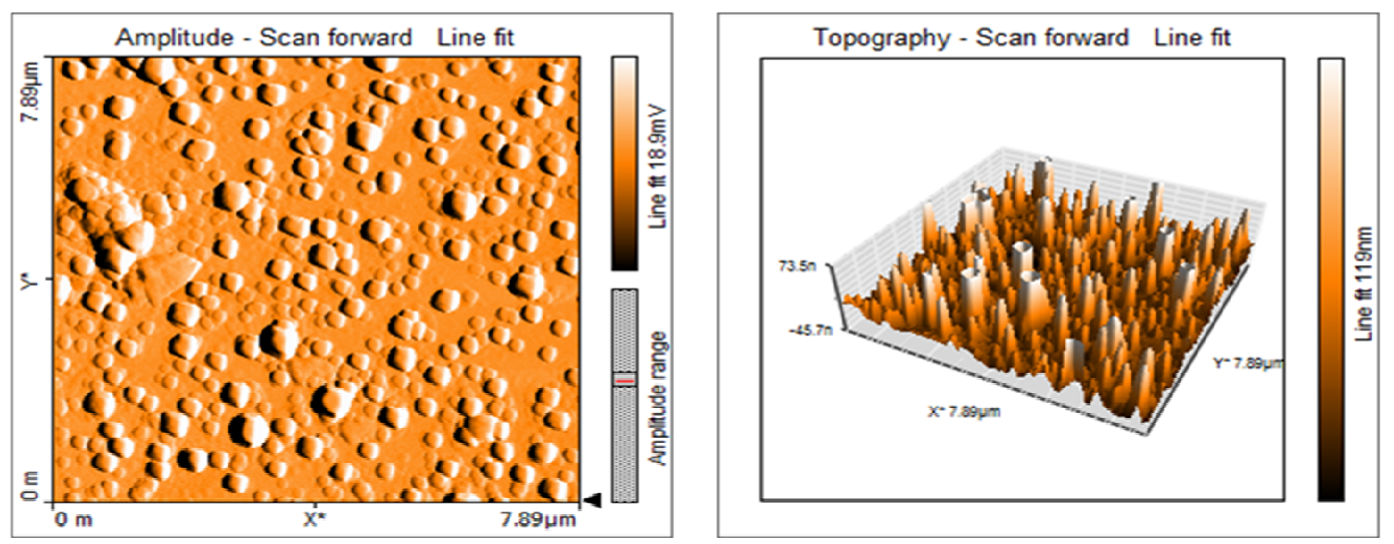

A

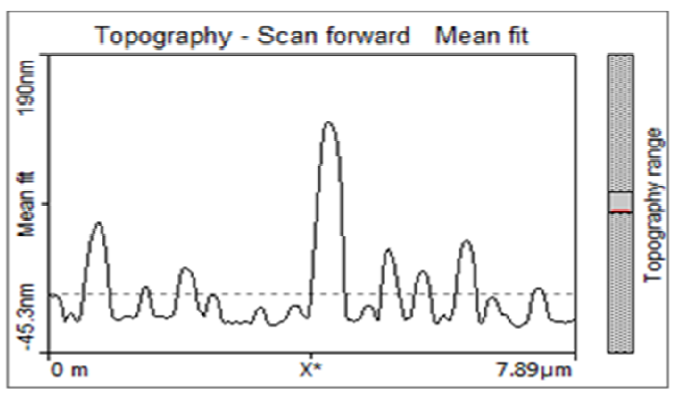

B

$\mathrm{C}$

Fig. 12 Shows the AFM images of AgNPs (A) Prospective image showing evenly spread spherical nanoparticles (B) Top view three dimensional symmetrical image of AgNPs (C) Topography scan. 
Fig.13 represents absorption spectrum of the Streptomyces supernatant solution and the peaks are of distinctive secondary metabolites present in the reaction solution. The cell free supernatant extract shows major absorption peaks in UV region from 190-380 $\mathrm{nm}$ of all available functional groups of the secondary metabolites present in the reaction mix. Due to the availability of all these diverse assemblage of the compounds in the reaction, bioreduction of silver ions $\left(\mathrm{Ag}^{+}\right)$to $\mathrm{AgNPs}\left(\mathrm{Ag}^{0}\right)$ nanoparticles acquire during the fabrication process. Efficient cluster of bioactive molecules like highly polyene nature antibiotic groups along with the other existing siderophores, present in the supernatant solution might also diminish extra and additional of silver ions to elemental silver [18-20]. Further; these nanoparticles are probably capped and stabilized during autoclaving, through the complex compounds which are secreted by Streptomyces genus during its life cycle development [21].

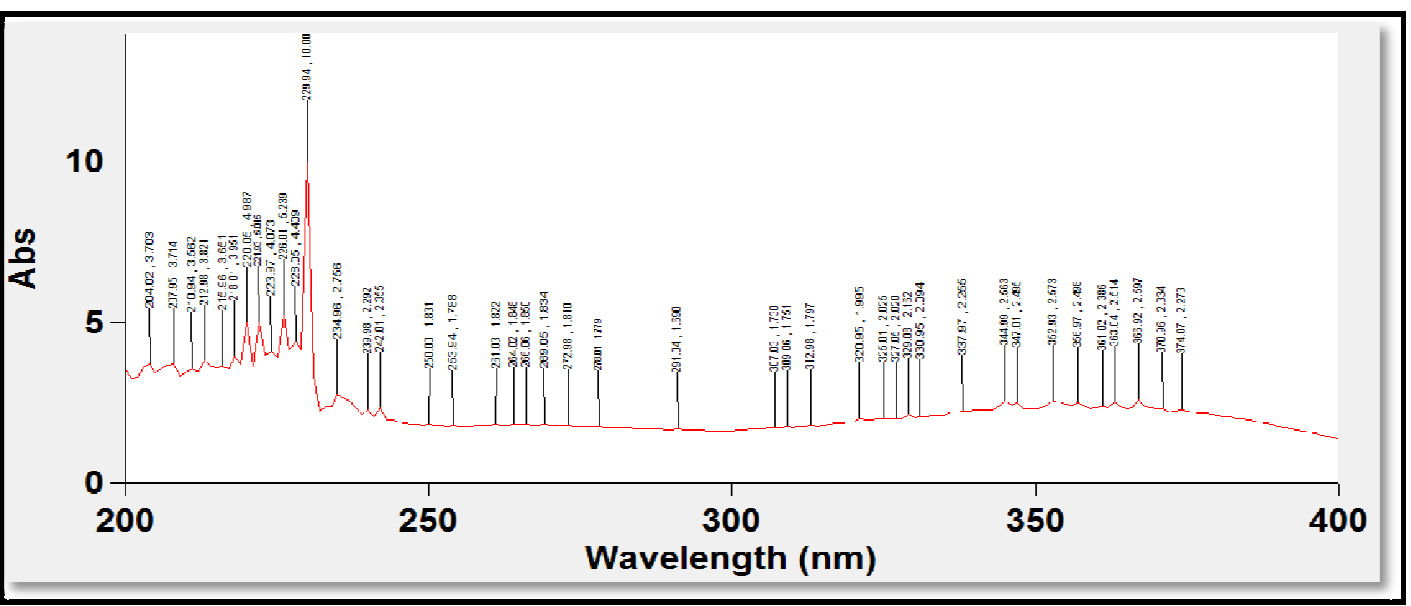

Fig. 13 Absorption Spectra of Streptomyces sp.GUT 21 supernatant extract showing the presence of diverse secondary metabolites.

FTIR molecular fingerprint spectrum was obtained in the wavelength range from 500 to $4000 \mathrm{~cm}^{-1}$ of silver nanoparticles as shown in Fig. 14. The peaks appeared at $3727 \mathrm{~cm}^{-1}$ and $3434 \mathrm{~cm}^{-1}$ (strong $\mathrm{O}-\mathrm{H}$ bonding) signifies the presence of $\mathrm{O}-\mathrm{H}$ stretching of carboxyl groups. Further, these peaks also indicate the presence of bonded hydroxyl groups designating the functional groups of alcohols and phenols. The peaks absorbed at $2924 \mathrm{~cm}^{-1}$ and $2851 \mathrm{~cm}^{-1}$ represent the $\mathrm{C}-\mathrm{H}$ stretching bonds. The peaks detected at $1750 \mathrm{~cm}^{-1}$, and $1631 \mathrm{~cm}^{-1}$, represents the $\mathrm{C}=\mathrm{O}$ stretch, $-\mathrm{C}=\mathrm{C}$ stretch of esters and amide group respectively, which corresponds to heterocyclic compounds like proteins. This serves as a support for proteins present in the supernatant as capping agents for the biosynthesized AgNPs [22-25]. It has been reported that proteins may bind to the nanoparticles either with the free amine groups or cysteine residues and cap the nanoparticles [26-29]. The peaks at $1420-1226 \mathrm{~cm}^{-1}$ represent the $\mathrm{C}-\mathrm{H}$ stretching vibrations, $\mathrm{N}-\mathrm{H}$ bending, $-\mathrm{CH}_{3}$ wagging and $\mathrm{C}-\mathrm{OH}$ stretching vibrations whereas the sharp peaks appeared at $1032 \mathrm{~cm}^{-1}$ and $711 \mathrm{~cm}^{-1}$ represent the C$\mathrm{O}$ stretching and aromatic $-\mathrm{CH}$ deformation respectively. Based on the spectrum fingerprint, in the present study, it can be inferred that many functional groups are involved in the conversion of silver ions to silver nanoparticles. The disappearance of the band or intensity decrease, such as the band at $1461 \mathrm{~cm}^{-1}$ and $469 \mathrm{~cm}^{-1}$ can also be accredited to the bioreduction of silver ions.

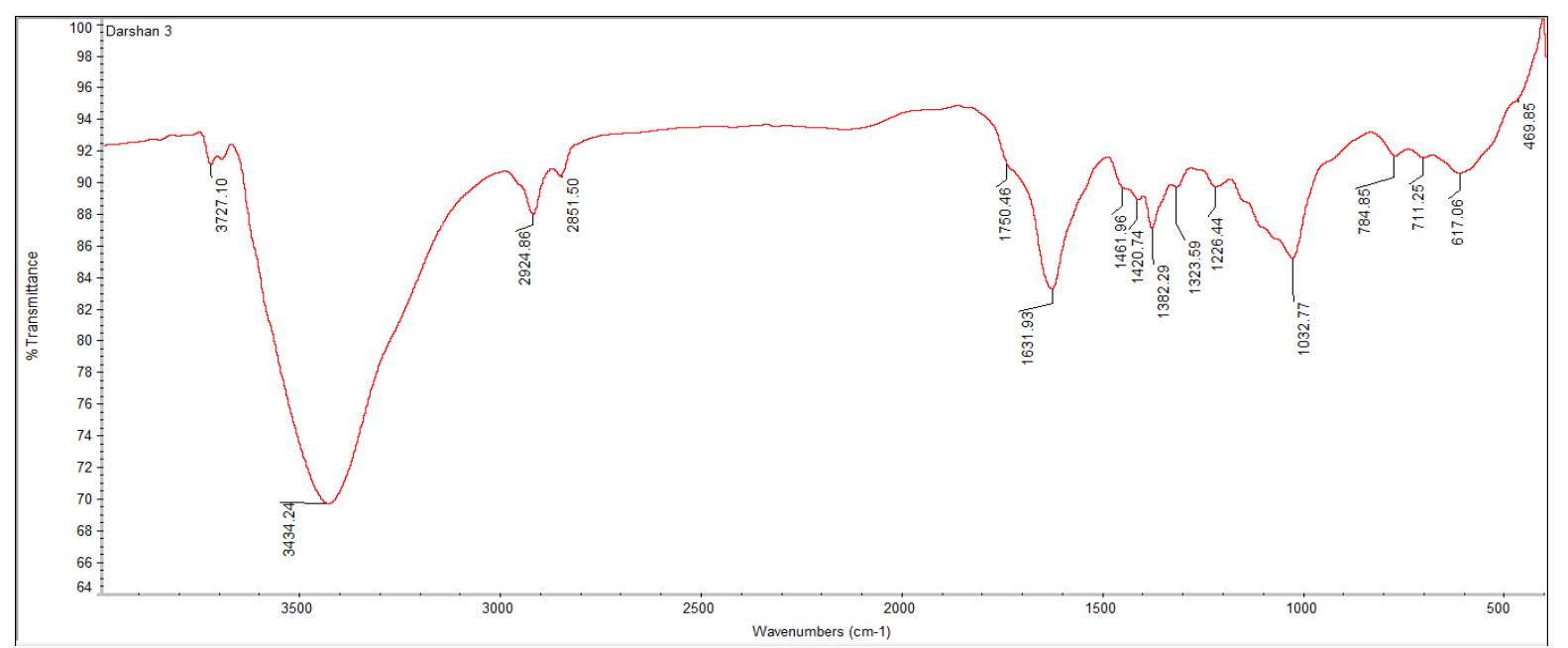

Fig. 14 FT-IR spectrum of freeze dried AgNPs synthesized using cell free supernatant of Streptomyces sp. GUT 21 
In recent scenario, microbial contamination has caused key hazards to public domain. Thus, with the appearance of multi-drug resistant (MDR) organisms to various antimicrobial agents [30] there is an improved requirement for enhanced disinfection techniques. Hence, serious challenges have been mounted on researchers to pave a way to find out alternatives from metal nanoparticles for disease control. Although, various reports are available on the synthesis of silver nanoparticles (AgNPs), concerted efforts must be invested in the factors involved in synthesis or the different factors involved in development of nanoparticles. The influential parameters like temperature, $\mathrm{p}^{\mathrm{H}}$, initial precursor concentration $\left(\mathrm{AgNO}_{3}\right)$ and water dilution do play a deciding factor in stability and storage of nanoparticles. Thus, in the present investigation much attention was given on the different parameters involved in the fabrication process. This study employed Streptomyces species supernatant extract, which was successfully utilised to synthesise silver nanoparticles (AgNPs) by autoclaving method. By optimizing the synthesis process and standardising the diverse parameters, uniformed size smaller nanoparticles were synthesized to suit various diagnostic applications.

\section{CONCLUSION}

Subsequently, it is concluded from the present study that Actinomycetes aqueous extract (Streptomyces sp.GUT 21, KU500633) can be exploited for the synthesis of silver nanoparticles by utilising the supernatant fraction. It was confirmed that, from the UV-Visible absorption spectrum, AFM analysis and X-ray diffractogram for the presence of silver nanoparticles formed from the reaction mixture with colloidal silver salt $\left(\mathrm{AgNO}_{3}\right)$ solution by autoclaving process. Valiant efforts are in progress in our laboratory for purification and downstream processing of these silver nanoparticles to recognize their potential reciprocal action with silver ions. Since the silver nanoparticles (AgNPs) produced are reliable and cost-effective they are being explored for various bitter sweet biological activities (like anti-diabetic and anti-cancerous) for addressing medical applications which is under evaluation.

\section{ACKNOWLEDGEMENT}

Authors are grateful Department of Biotechnology, Gulbarga University, Gulbarga for providing facilities for pursuing the research work. We are also indebted to Department of Biotechnology (DBT) for providing fellowship to carry out research work at University of Agricultural sciences (UAS), Dharwad.

\section{REFERENCES}

[1]Le AT, Huy PT, Dinh Tam P, Quang Huy T, Dac Cam P, Kudrinskiy A A, Krutyakov YA 2010 Green synthesis of finely-dispersed dispersed highly bactericidal silver nanoparticles via modified Tollens technique, J Appl Phys, 10, 910-916.

[2]Hebeish A, El-Shafei A, Sharaf S, Zaghloul S 2011 Novel precursors for green synthesis and application of silver nanoparticles in the realm of cotton finishing. Carbohydr Polym, 84, 605-613.

[3]Soukupov J, Kvytek L, Panacek A, Nevecna T, Zboril R, 2008 Comprehensive study on surfactant role on silver nanoparticles (NPs) prepared via modified Tollens process. Mater Chem Phys, 111, 77-81.

[4] Kalimuthu, K., Deepak, V., Ramkumarpandian, S., Nellaiah, H. and Sangiliyandi, G, 2008, Extracellular biosynthesis of silver nanoparticles by the culture supernatant of Bacillus licheniformis, Mat. Lett., 62, pp. 4411-4413.

[5] Saifuddin, N., Wong, C.W. and Nur Yasumira, A.A, 2009, Rapid biosynthesis of silver nanoparticles using culture supernatant of bacteria with microwave irradiation, J. Chem., 6, 61-70.

[6] Shivaji, S., Madhu, S. and Singh, S, 2011, Extracellular synthesis of antibacterial silver nanoparticles using psychrophilic bacteria, Process. Biochem., 6, 1-32.

[7] El-Batal A. I., Mohamed Helal El-Sayed, Bahgat Mohamed Refaat, Ahmed Abdel Zaher Askar, 2014, Marine Streptomyces cyaneus Strain Alex-SK121 Mediated Ecofriendly Synthesis of Silver Nanoparticles Using Gamma Radiation. British Journal of Pharmaceutical Research 4(21), 2525-2547.

[8] Sengupta, S. Eavarone, D. Capila, I. Zhao, G.L. Watson, N., Kiziltepe, T., et al. 2005, Temporal Targeting of Tumor Cells and Neovasculature with a Nanoscale Delivery System. Nature, 436, 568-572.

[9]Knoll, B. \& Keilmann. F, 1999, Near-field probing of vibrational absorption for chemical microscopy. Nature, 399, 134-137.

[10]Wiley B, Sun Y, Xia Y, 2007, Synthesis of Silver Nanostructures with Controlled Shapes and Properties. Acc. Chem. Res. 40(10), 1067-1076.

[11]Gao, X., Gu, G., Hu, Z., Guo, Y., Fu, X., Song, J, 2005, A Simple Method for Preparation of Silver Dendrites Colloids and Surfaces A: Physicochemical Engineering Aspects 254, $57-61$.

[12]Atta, H. M., Dabour, S. M. and Desoket, S. G,2009, Saprosomycin antibiotic production by Streptomyces sp AZNIOFD1: Taxonomy, Fermentation, Purification and Biological Activities, American Eurasian, Journal of Agriculture and Environmental Sciences 5, 368- 377.

[13]Oskay M., Tamer A.U. and Azeri C, 2004, Antibacterial activity of some actinomycetes isolated from farming soils of Turkey, African J Biotechnol .3 (9).441- 446.

[14]Huanga NM, Lim HN, Radiman S, Khiew PS, Chiu WS, Hashim R, Chia CH, 2010, Sucrose ester micellarmediated synthesis of $\mathrm{Ag}$ nanoparticles and the antibacterial properties. Colloids Surf A 353, 69-76.

[15]Kantrao Saware, Balaji Sawle, Basavraja Salimath, Kamala Jayanthi, Venkataraman Abbaraju, 2014, International Journal of Research in Engineering and Technology, Volume, 03 Issues, 05, 867-874.

[16] S P Dubey, M Lahtinen, H Sarkka and M Sillanpaa, 2010, Bioprospective of Sorbus aucuparia leaf extract in development of silver and gold nanocolloids Colloids Surf. B. 80 26-33.

[17]Aruna Jyothi Kora, Sashidhar Rao Beedu and Arunachalam Jayaraman, 2012, Size-controlled green 
synthesis of silver nanoparticles mediated by gum ghatti (Anogeissus latifolia) and its biological activity. Organic and medicinal chemistry 2, 17-27.

[18] Slavica B. Ilić, Sandra S. Konstantinović, Zoran B. Todorović, 2005, UV/VIS analysis and antimicrobial activity of Streptomyces isolates. Medicine and Biology Vol.12, No 1, pp. $44-46$.

[19] Hadi Maleki, Omid Mashinchian, 2011, Characterization of Streptomyces Isolates with UV, FTIR Spectroscopy and HPLC Analyses. BioImpacts, 1(1), 47-52. [20] Silvia D Schrey, Eric Erkenbrack, Elisabeth Früh, Svenja Fengler, Kerstin Hommel, Nadine Horlacher , Dirk Schulz, Margret Ecke, Andreas Kulik, Hans-Peter Fiedler, Rüdiger Hampp and Mika T Tarkka1,2012, Production of fungal and bacterial growth modulating secondary metabolites is widespread among mycorrhiza-associated Streptomycetes, BMC Microbiology 12:164-178.

[21] V.S. Nikitina, L.Y. Kuz'mina, A.I. Melent'ev, G.V. Shendel, 2007, Antibacterial Activity of Polyphenolic Compounds Isolated from Plants of Geraniaceae and Rosaceae Families,Appl. Biochem. Microbiol.43, 629-634.

[22] P. Kannan, S.A. John, 2008, Synthesis of mercaptothiadiazole functionalized gold nanoparticles and their self-assembly on Au substrates, Nanotechnology 19 085602.

[23] S.C. Whiteman, Y. Yang, J.M. Jones, M.A. Spiteri, 2008, FTIR spectroscopic analysis of sputum: Preliminary findings on a potential novel diagnostic marker for COPD,Ther. Adv. Respir. Dis. 2, 23-31.

[24] M. Sastry, A. Ahmad, M.I. Khan, R. Kumar, 2003, Biosynthesis of metal nanoparticles using fungi and actinomycete, Curr. Sci. 85, 162-170.

[25] R. Sanghi, P. Verma, 2009, Biomimetic synthesis and characterisation of protein capped silver nanoparticles, Bioresour. Technol. 100, 501-504.

[26] A. Gole, C.V. Dash, V. Ramachandran, A.B. Mandale, S.R. Sainkar, M. Rao, 2001,Pepsin-Gold Colloid Conjugates: Preparation, Characterization, and Enzymatic Activity,Langmuir 17, 1674-1679.

[27] S.S. Shankar, A. Ahmad, R. Pasricha, M. Sastry, 2003, Bioreduction of chloroaurate ions by geranium leaves and its endophytic fungus yields gold nanoparticles of different shapes,J. Mater. Chem. 13, 1822-1826.

[28] J. Xie, J.Y. Lee, D.I. Wang, Y.P. Ting, 2007, Silver Nanoplates: From Biological to Biomimetic Synthesis, ACS Nano 1, 429-439.

[29] M. Gajbhiye, J. Kesharwani, A. Ingle, A. Gade, M. Rai, Nanomed, 2009, Fungus-mediated synthesis of silver nanoparticles and their activity against pathogenic fungi in combination with fluconazole, NBM 5,382-386.

[30]Kolar M, Urbanek K, Latal T, 2001, Antibiotic selective pressure and development of bacterial resistance. Int $\mathbf{J}$ Antimicrob Ag, 17,357-363. 